\title{
LA FALSA IMAGEN DEL ESPAÑOL AMERICANO
}

\author{
Juan M. Lope Blanch \\ Universidad Nacional de México \\ El Colegio de México
}

0.1. Cuando, en 1964, sometí a la consideración de la Comisión de Lingüística Iberoamericana, del Programa Interamericano de Lingüística y Enseñanza de Idiomas, el proyecto de estudio del habla culta de las principales ciudades de Hispanoamérica ${ }^{1}$, me impulsaba a ello la creencia de que el español hablado en América era, todavía, "un ilustre desconocido". No obstante lo mucho que, sin duda, ha progresado durante los últimos lustros nuestro conocimiento de las modalidades lingüísticas hispanoamericanas, sigo pensando que muchas de ellas son aún sólo parcialmente - cuando no erróneamente- conocidas. Deficiencia o error que alcanza, en algunas ocasiones, al "español de América" en su totalidad.

Así, la caracterización general que suele hacerse del español americano presenta una imagen un tanto distorsionada, que debe ser corregida o, al menos, mejor delineada. Convendría matizar y aun superar algunas de las ideas expuestas, ya en 1949, por Max Leopold Wagner ${ }^{2}$, que filólogos actuales repiten al pie de la letra como verdades incuestionables. De acuerdo con ellas, el español de América quedaría caracterizado por los siguientes rasgos definitorios: su sorprendente uniformidad, su firme conservadurismo, su básica rusticidad o vulgarismo, su colorido amerindio, su originario arcaísmo y su parcial andalucismo.

1 Fue recogido en las Actas del Simposio de Bloomington que publicó el Instituto Caro y Cuervo de Bogotá en 1967 (v. págs. 255-264). Está también incluido en mi libro El estudio del español culto hablado: Historia de un Proyecto, México, UNAM, 1986, págs. 9-19.

2 Cfr. su libro Lingua e dialetti dell'America spagnola, Firenze, Le Lingue Estere, 1949. 
0.2. La reformulación de estas consideraciones ha sido hecha, de manera precisa, por Zamora Vicente, sin hacer referencia expresa a lo escrito por Max Leopold Wagner. En relación con la supuesta uniformidad del español americano, Zamora Vicente afirma: "El español americano presenta ... una sólida homogeneidad sobre todo dentro de los niveles cultos. Las diferencias son más marcadas en las capas semicultas y vulgares. A pesar de todo, las diferencias, dentro del enorme territorio americano, son minimas dentro de la estructura total del habla. Hay muchas menos diferencias entre dos regiones cualesquiera de la enorme América, por separadas que se encuentren, que entre dos valles vecinos de Asturias, por ejemplo. A lo largo del Nuevo Mundo, desde Nuevo Méjico a la Tierra del Fuego, los fenómenos fonéticos se repiten. Algunas regiones denotan alguna preferencia por éste o por el otro fenómeno, pero todos existen en todas partes, y, por añadidura, todos son conocidos en el español peninsular" 3 . Palabras que repiten, de manera más radical y extremosa, lo dicho por Wagner: "lo spagnolo americano rivela, almeno nelle sue fondamenta basilari, una assai grande unità e omogeneità ... Non sempre quest'omogeneità è perfetta: alcune regioni hanno una preferenza per tale o talaltro fenomeno fonetico che manca o è raro in altre zone; ma, grosso modo, si può dire che la maggioranza dei fenomeni si ritrova un po' in tutte le regioni del vasto continente" 4 .

De todo ello se podrían extraer varias conclusiones: a) Que, dada la "sólida homogeneidad" de las hablas americanas, cabe seguir insistiendo en la existencia de un español americano como modalidad lingüística uniforme, muy alejada de la enorme variedad idiomática de la Península Ibérica; b) Que esa modalidad hispanoamericana de la lengua española carece de originalidad, al menos en el plano fonético, ya que no presenta ningún rasgo propio, independiente del español europeo y desconocido en él ; c) Esta dependencia inmediata con respecto al tronco peninsular explica el profundo conservadurismo del español americano y su incapacidad de originar innovaciones fonéticas.

El tercer rasgo característico del español americano, su rusticismo o vulgarismo, sería consecuencia natural de la baja extracción social y cultural de los colonizadores de América. Siendo el castellano transplantado al Nuevo Mundo el "español anteclásico" y considerando — como hace Wagnerque "se lo spagnolo ha sempre avuto una inclinazione verso il popolarismo, la lingua preclassica è particolarmente propensa a questa tendenza. Alla pro-

3 Alonso Zamora Vicente, Dialectología española, 2." ed., Madrid, Gredos, 1967, págs. 378-379.-Los subrayados son míos.

4 Lingua, pág. 12. Y, tras hacer la enumeración de 15 fenómenos de carácter fonético probatorios de su opinión, añade: «Tutti questi sono fenomeni che si trovano nei testi dell'epoca preclassica e nei dialetti spagnoli attuali ed anche nel giudeo-spagnolo d'Oriente» (págs. 13-14). 
pagazione della lingua popolare e provinciale contribui anche il fatto che la massa di avventurieri e guerrieri che, nei primi decenni dopo la conquista, si riversarono in America, consisteva per lo più di gente rozza e poco colta" (cfr. Lingua, pág. 11). Consideración que reitera Zamora Vicente, al explicar que "la fuerte inclinación hacia el léxico y los fenómenos fonéticos del aire popular o vulgar" se debe al "origen de los primeros pobladores y conquistadores, de clases sociales poco refinadas", cosa que explicaría también que "la vida de la colonia se redujera de contenido frente a la metrópoli" (cf. Dialectología, págs. 378 y 428).

La cuarta característica de ese homogéneo, conservador y rústico o vulgar español americano - su vivo colorido amerindio- es el resultado de la profunda influencia ejercida por las lenguas indoamericanas sobre la lengua de Castilla; esto es, el efecto de los sustratos amerindios. Mestizaje lingüístico que era consecuencia inmediata del mestizaje étnico que se produjo en el Nuevo Mundo cuando aquella "gente rozza e poco colta ... contrasse spesso matrimonî con donne indiane” (Wagner, pág. 12).

Otra peculiaridad definitoria del español americano sería su acusado arcaísmo, debido al hecho de que esta modalidad de la lengua castellana procede y es continuación del español medieval, de fines del siglo xv: "Lo spagnolo importato in America fu naturalmente quello dell'epoca della conquista, ciò̀ il cosiddetto spagnolo preclassico ... La lingua spagnola anteriore alla conquista dell'America non aveva ancora raggiunto il culmine del suo sviluppo letterario. I grandi scrittori della nazione spagnola, Cervantes, Lope de Vega, Tirso de Molina, Alarcón, Quevedo, Calderón, Gracián, ecc. i quali ... appartengono al secolo seguente" (Wagner, pág. 11). Idea de que vuelve a hacerse eco Zamora Vicente: "El fundamento del español americano está, naturalmente, en el llevado al Nuevo Mundo por los conquistadores. Ese castellano es el preclásico, la lengua de fines del siglo xv, la usada por Mena, Manrique y La Celestina, y codificada en la Gramática de $\mathrm{Ne}$ brija. Es decir, una lengua anterior al esfuerzo creador de las grandes personalidades de los Siglos de Oro" (pág. 378).

Por último, caracteriza al español de América cierto andalucismo de base, consecuencia del elevado número de conquistadores y colonizadores procedentes de Andalucía, en especial, durante las primeras etapas de la época virreinal.

1.0. No obstante el fondo de verdad que pueda haber en algunas de estas apreciaciones sobre el español hablado en América, considero que simplifican ellas, en gran medida, la realidad lingüística americana, cuando no la deforman y aun alteran radicalmente. Pienso, en consecuencia, que esa 
caracterización de las hablas hispanoamericanas debe ser precisada o matizada en unos casos e, inclusive, rechazada en otros. Tal cosa es lo que pretendo hacer aquí muy concisamente, ya que hacerlo con algún pormenor exigiría llevar a cabo un estudio amplio sobre la compleja situación que guarda la lengua española en "la enorme América", lo cual sería tarea que rebasaría totalmente los estrechos límites de un artículo.

1.1. El primero de los rasgos caracterizadores del español americano - su homogeneidad o uniformidad - necesita ser matizado en gran medida. Si lo que se quiere decir es que los hispanoamericanos pueden todavía entenderse entre sí cualquiera que sea su procedencia nacional, ello es indiscutiblemente cierto. Todos seguimos hablando - juntamente con los españolesuna misma lengua. Pero de ahí a decir que el español de la enorme América es sólidamente homogéneo media un abismo o, al menos, una buena barranca. $\mathrm{Y}$ sostener que las diferencias lingüisticas que puedan existir entre dos regiones alejadas de América serán siempre menores que las que existen entre dos valles vecinos de Asturias podría ser ya simple dislate.

Manteniéndonos dentro del reducido marco de la fonética - sin necesidad de incursionar en el mundo más amplio y complejo del léxico o de la sintaxis- podremos advertir que esa supuesta uniformidad está muy lejos de corresponder a la realidad de las hablas hispanoamericanas. Me limitaré a recordar algunas peculiaridades de ciertos dialectos americanos que son desconocidas en los otros y que rompen, en consecuencia, esa supuesta homogeneidad.

La palatalización de los fonemas velares, sordo $\mathrm{y}$ sonoro $-/ \mathrm{x} / \mathrm{y} / \mathrm{g} /$ con desarrollo inclusive de una yod, en casos como [ $x$ 'jénte] o [g'jéra], es rasgo peculiar del español hablado en Chile y desconocido - que yo sepaen el resto de Hispanoamérica.

Las realizaciones americanas del fonema palatal lateral $/ 1 /$ determinan una fragmentación geográfica muy acusada: de un lado, regiones en que la articulación lateral se ha mantenido como tal, según sucede en buena parte de Colombia, en todo el Paraguay y amplias zonas de Bolivia, así como en parte del Ecuador, del Perú, de la Argentina y de Chile; de otro lado, las zonas - que forman mayoría - en que la lateral se ha confundido con la central /y/, como sucede, por ejemplo, en casi todo el territorio mexicano; de otra parte, las regiones sudamericanas en que la articulación neutralizada se realiza con fuerte rehilamiento /ž/, cosa que también se conoce en partes de México, solución a que hay que añadir la rioplatense - de la Argentina y del Uruguay - ensordecida o plenamente sorda /š/; de otro lado, las regiones en que el resultado de la nivelación ha sido una semiconsonante, palatal muy abierta / $\mathrm{V} /$, como sucede en el español del Suroeste norteamericano 
y en otras muchas zonas de Hispanoamérica, en especial las costeras; de otro lado aún, regiones en que la articulación suele ser africada $/ \hat{y} /$, como sucede en el Paraguay, parte de la Argentina y de México; y, por último, comarcas en que parece haberse establecido una distinción entre $/ y /-/ \check{z} /$, procedente la primera de $/ y /$ castellana y de $/ 1 /$ la segunda, oposición peculiar de parte de la Sierra ecuatoriana y de Santiago del Estero en la Argentina ${ }^{5}$.

Los fonemas vibrantes han sufrido también una rica serie de transformaciones en las diversas hablas americanas, que van desde su articulación normal como vibrantes, a su asibilación, ya como sonora $/ \check{\bar{r}} /$, ya como sorda $/ \overline{\bar{r}} /$, en grandes zonas del interior de la Argentina, de Chile, de Centroamérica y aun de México, pasando por soluciones más restringidas, como la de su velarización $[\boldsymbol{\Re}]$ - común en Puerto Rico- o como su neutralización con la lateral $/ 1 /$-frecuentísima en Cuba o en el mismo Puerto Rico-, hasta llegar a la articulación retrofleja [r] que se practica en el español de Yucatán al menos.

Peculiar del Paraguay parece ser la articulación labiodental / $/$ tanto para /v/ cuanto para /b/ originarias, fenómeno debido tal vez a la influencia del guarani, y que sería privativo del español paraguayo ${ }^{6}$.

La heterogeneidad en el dominio fonético no se da sólo entre unos países $\mathrm{y}$ otros de Hispanoamérica, sino que puede hallarse entre diversas regiones de un mismo país. Tal es el caso, por ejemplo, del dialecto yucateco en relación con las demás hablas del español mexicano. Manteniéndome dentro del dominio fonético, hallo en la modalidad lingüistica yucateca varias realizaciones que o son totalmente desconocidas en el resto de las hablas hispanoamericanas o muy ocasionales y débiles en ellas: 1) Ante todo, las frecuentes clausuras glóticas - procedentes de la lengua maya-, que pueden aparecer en cualquier posición elocutiva: entre vocales [lapóra], entre consonantes [dós?días], entre unas y otras [las?ágwas], [mi?kása], al final de grupo fónico ante pausa [éso nó?] o al comienzo de elocución [? algo pása] ${ }^{7}$; 2) las sorprendentes - aunque muy ocasionales - consonantes glotalizadas, de procedencia también maya, que sólo hemos detectado en el español de Yucatán: /t', č', p', k'/ en casos como [t'jémpo], [č'íko], [p'áse], [k'ómo] ${ }^{8}$;

- Cfr. Rafael Lapesa, Historia de la lengua española, Madrid, 8." ed., Gredos, 1980, $\S 130$.

- Cfr. Germán de Granda, «Observaciones sobre la fonética del español en el Paraguay», $A L, \mathrm{XX}, 1982$, págs. 145-194. (Véanse en especial págs. 155-157.) Este artículo ha sido incluido en su libro sobre Sociedad, historia y lengua en el Paraguay, Bogotá, Instituto Caro y Cuervo, 1988, págs. 109-156.

7 Cfr. mi estudio «Sobre los cortes glóticos del español yucateco» en el Homenaje a Luis Flórez, Bogotá, Instituto Caro y Cuervo, 1984, págs. 199-219.

${ }_{8}$ De ello me he ocupado en mi trabajo «Sobre glotalizaciones en el español de Yu- 
3) la altísima frecuencia de articulaciones oclusivas de las sonoras /b,d,g/ en posición intervocálica [lába, tódo, lágo] ; 4) la despalatización de $/ \mathrm{n} /$ en casos como [lénja] 'leña', [mónjo] 'moño', o [albaníl] 'albañil'; 5) la labialización de /-n/ final de palabra, especialmente ante pausa: [pám], [Yucatám] ; 6) la articulación de la fricativa /f/ como oclusiva /p/ o como africada $[\hat{\varphi}]:$ [empérmo] o [ழ̣antásma] ; 7) la —ocasional- articulación retrofleja de $/ \mathrm{r} /$ implosiva [kárne] $^{9}$.

Bastan -me parece- estos ejemplos particulares para mostrar cuán lejos de la realidad está la tesis relativa a la firme y sólida homogeneidad del español de América. No obstante lo cual, aunque no exista verdadera uniformidad lingüística en el ancho mundo hispanoamericano, "la impresión de comunidad general - como bien ha señalado Rafael Lapesa ${ }^{10}$ - no está injustificada: sus variedades son menos discordantes entre sí que los dialectos peninsulares, y poseen menor arraigo histórico".

Hace así el profesor Lapesa referencia a uno de los factores que poseen, en mi opinión, mayor importancia en el proceso de análisis de esa cuestión: "la impresión de comunidad general" del español americano. Y, como ya he comentado en otra ocasión ", creo que, en efecto, existe esa impresión y que está ampliamente generalizada. Pero podría suceder que tal impresión fuera engañosa. "La impresión — de homogeneidad o de heterogeneidad- que el conjunto de hablas hispanoamericanas pueda producir en el observador depende de varios factores: De su real y verdadera uniformidad o variedad, por supuesto. Pero también de la capacidad de juicio, de la capacidad de discernimiento por parte del observador. Y ésta, a su vez, está determinada por el grado de familiaridad del observador para con los hechos. Y si el observador es un especialista, un estudioso - un filólogo, en suma- su capacidad de juicio estará también condicionada, lógicamente, por el número de datos, por los elementos de juicio de que disponga. Y es el caso que la filología hispanoamericana no ha proporcionado todavía información seria y precisa sobre las hablas de muchos y muy variados territorios de Hispanoamérica. Y sobre otros, ya estudiados, proporciona a veces informaciones par-

catán», Philologica Hispaniensia in honorem Manuel Alvar, vol. I (Dialectologla), Madrid, Gredos, 1983, págs. 373-386.

- Cfr. los estudios de Víctor M. Suárez, El español que se babla en Yucatán, Mérida, 1945 (2." ed., 1979); Manuel Alvar, «Nuevas notas sobre el español de Yucatán», Iberoromania, I, 1969, págs. 159-189; Josefina García Fajardo, Fonética del español hablado en Valladolid, Yucatán, México, UNAM, 1984; Juan M. Lope Blanch, Estudios sobre el español de Yucatán, México, UNAM, 1987.

${ }^{10}$ Cfr. su Historia de la lengua, pág. 534 de la 8.* ed.

11 Cfr. «Fisonomía del español en América: Unidad y diversidad», en Actas del I Congreso Internacional sobre el español de América, San Juan, Puerto Rico, Academia Puertorriqueña de la Lengua Española, Madrid, 1987, págs. 59-78. 
ciales, cuando no superficiales y aun erróneas. El lingüista se encuentra, así, sólo parcialmente capacitado para hacer sus evaluaciones.

El observador común, por su parte, evalúa — como decía- de acuerdo con su capacidad de discernimiento, según su personal familiaridad con los hechos. Los lingüistas españoles - muchos de los cuales han prestado reiterada atención a las hablas hispanoamericanas- están naturalmente más familiarizados con las modalidades dialectales de la Peninsula Ibérica -las cuales, además, han sido más y mejor estudiadas y descritas - que con las de Hispanoamérica - menos y peor estudiadas que aquéllas. En consecuencia, no es de extrañar que su impresión sea favorable a la tesis de una mayor homogeneidad de las hablas americanas.

Pero esa capacidad de discernimiento, esa familiaridad con unas y otras hablas hispánicas, cambia de persona a persona." Los españoles pueden estar bien capacitados, por sus simples experiencias lingüisticas cotidianas, a distinguir el habla de andaluces, aragoneses, castellanos, catalanes (hablantes de español, claro está), gallegos, canarios, etc., pero no tendrán la misma capacidad de discernimiento - por simple falta de familiaridad - en el caso de las hablas hispanoamericanas. Mas, paralelamente, a los hispanoamericanos les puede resultar muy difícil distinguir las diversas hablas peninsulares, pero tendrán mayor capacidad de discernimiento en el caso de las americanas, de manera que un cubano no confundirá su habla con la de un puertorriqueño o un dominicano, ni mucho menos con la de un mexicano, argentino, chileno o peruano. Sin olvidar, por otra parte, que las hablas antillanas producen la impresión —creo que justificada - de estar más próximas a las hablas meridionales y atlánticas de España que a las de otras regiones de América, como México o el Ecuador, por ejemplo.

Es imprescindible, pues, seguir estudiando rigurosa y sistemáticamente la realidad lingüística de América, con objeto de poder llegar algún día a contar con los elementos de juicio necesarios para hacer una evaluación precisa y realista. De lo contrario, seguirá vigente la observación de José $\mathrm{P}$. Rona: "Esta llamada homogeneidad del español americano se ha convertido ya en lugar común y, como tal, no suele ser examinada en cuanto a su veracidad o falsedad. Se trata de uno de los numerosos mitos que circulan en este terreno, y que creemos poder atribuir al hecho de que se empezara a hablar y escribir del español americano antes de conocerse el español americano" 12 .

Por otro lado, cuando se compara el complejo mosaico lingüístico que es la Península Ibérica con la situación de Hispanoamérica, se establece una

12 Cfr. su ensayo sobre $* E l$ problema de la división del español americano en zonas dialectaless, en Presente y futuro de la lengua española (Actas del I Congreso de Instituciones Hispánicas), Madrid, Eds. Cultura Hispánica, vol. I, 1964, pág. 215. 
comparación inadecuada e impertinente. Se pasa por alto el hecho de que castellano, catalán, gallego y bable son sistemas lingüisticos derivados de la lengua latina, en tanto que en Hispanoamérica sólo existen sistemas lingüísticos derivados del castellano o - a partir del siglo xvI- integrantes, más precisamente, del español. Los términos de comparación adecuados serían, por un lado, las variantes peninsulares e insulares de la lengua española (castellana, andaluza, extremeña, aragonesa, murciana, canaria, etc.) y, por otro lado, las variantes americanas de esa misma lengua (cubana, puertorriqueña, mexicana, argentina, chilena, colombiana, etc.). $\mathrm{Y}$ entonces advertiriamos que tan nítidamente diferenciadas como pueden ser las variantes españolas, lo son también las variantes americanas, inclusive dentro de un mismo país, como acabo de apuntar respecto del español mexicano de Yucatán. Y ello, sin conceder demasiado valor a la prueba de la "intercomprensibilidad" a que hacía referencia el profesor Rona atendiendo al caso de la población monolingüe de la zona de Las Tacanas, en la argentina provincia de Tucumán, cuya habla era "virtualmente ininteligible incluso para profesores tucumanos natos que lo acompañaban en sus investigaciones. Esto sucedía a pesar de estar situada la zona de Las Tacanas a poco más de 50 kilómetros de la ciudad de [San Miguel de] Tucumán" ${ }^{13}$, o sea a tiro de piedra en relación con las gigantescas dimensiones de los territorios hispanoamericanos. Creo que a estos casos extremos de incomunicación no debe concedérseles demasiada importancia, dado que no reflejan la situación normal o común de nuestra lengua, dado también que pueden hallarse tanto en España como en América, y dado, sobre todo, que pueden obedecer, más que a diferencias diatópicas, a distinciones diastráticas.

1.2. Que el español de América sea muy conservador - esencialmente estático- es opinión que no puede sostenerse seriamente, al menos por el momento, aunque tampoco pueda negarse rotundamente. Para saber si el español americano es o no conservador, sería necesario completar una larga y compleja serie de investigaciones que todavía no se han cumplido y apenas si se han iniciado ${ }^{14}$. Sería preciso, en primer lugar, determinar objetivamen-

13 Cfr. «El problema de la división*, págs. 215-216.

14 Desde hace afios existe un ambicioso «Proyecto de estudio histórico del espafíol americanow que presenté a la consideración de los miembros de la Comisión de Lingǘfstica Iberoamericana (del Programa Interamericano de Lingülstica) reunida en Bogotá, en 1967, y que Guillermo L. Guitarte se esforź por delinear un año después. (De todo ello he dado noticia en una ponencia dedicada a ese «Proyecto» que presenté en el IX Congreso Internacional de la Asociación Internacional de Hispanistas -Universidade Estadual de Campinas, agosto de 1990 - y que se publicará en las Actas correspondientes.) El propio Guitarte amplió grandemente su exposición en una ponencia sobre las «Perspectivas de la investigación diacrónica en Hispanoaméricaw, incluida en el volumen que edité con el título de Perspectivas de la investigación lingüistica en Hispanoamérica, México, UNAM, 1980, págs. 119-137. 
te cómo era el español transplantado al Nuevo Mundo en el siglo xvi, cuáles eran las estructuras fonética, morfosintáctica y léxica del sistema castellano. A continuación habría que detectar puntualmente todas las innovaciones, todos los cambios que se han producido, desde el momento del transplante de la lengua, en las hablas de América, por un lado, y en las de España, por otro. Y determinar, por último, dónde han sido más cuantiosas tales transformaciones, si en España o en América.

Ahora bien, la idea de que el español americano sea una simple rama del español europeo, de la que no han surgido brotes nuevos que no hayan brotado también previamente en las ramas peninsulares, me parece más que discutible. Recordemos, en efecto, que las hablas americanas se han anticipado a las españolas en no pocas ocasiones, $\mathrm{y}$ que han llevado a la cúspide algunas innovaciones que apenas pugnan por establecerse en las hablas peninsulares o que son en ellas desconocidas. El rehilamiento de las palatales sonoras en el Río de la Plata y su posterior ensordecimiento $/ \check{\mathrm{s}} /$, la asibilación de $/ \overline{\mathrm{r}} /$ o / - r/ en grandes extensiones de territorio americano, la palatización de las velares sorda / $\mathrm{x} / \mathrm{y}$ sonora /g/ en Chile, la glotalización de los fonemas oclusivos sordos en Yucatán, la labiodentalización de toda labial sonora en el Paraguay, la velarización de $/ \overline{\mathrm{r}} /$ en Puerto Rico, etc., asi como la simplificación del paradigma verbal -especialmente de algunas formas del subjuntivo-, la creación de nuevas perífrasis verbales - del tipo "dar + gerundio" en el español del Ecuador ${ }^{15}$ - o su cambio de significado o valor - por ejemplo "ir + gerundio" como exhortativa, usual en México y en otros pai$\operatorname{ses}^{16}$ - entre otros hechos idiomáticos, son innovaciones que en España resultan totalmente desconocidas o no han adquirido todavía carta de naturaleza. Todo ello sin tomar en consideración la abundante creación léxica, la intensa derivación nominal y verbal, y las frecuentes alteraciones semánticas que se multiplican en el español americano ${ }^{17}$.

$\mathrm{Y}$ no podía haber sido de otra manera. Todo sistema lingüistico transplantado de un lugar a otro o echa raíces en la nueva tierra, o languidece y acaba por morir, posiblemente sofocado por la lengua autóctona. No ha sido este último, evidentemente, el caso del castellano en América, sino todo lo contrario: aquí arraigó con firmeza, se extendió con rapidez por amplios territorios y comenzó una vida nueva y vigorosa. Vida cada vez más independiente de la matriz peninsular, aunque no divergente en su esencia. Contra el lugar común de la dependencia del español americano respecto del europeo

\footnotetext{
15 En casos como «Dame haciendo mi trabajow: cfr. Humberto Toscano Mateus, El español en el Ecuador, Madrid, CSIC, 1953, págs. 284-285.

16 Además de otros valores -incoativo, terminativo, etc.- que anoté en mis Observaciones sobre la sintaxis del español bablado en México, México, 1953, §93, págs. 87-88.

17 Cfr. Charles E. Kany, American-Spanish Semantics, Berkeley and Los Angeles, University of California Press, 1960.
} 
se han levantado voces bien autorizadas desde hace ya bastante tiempo. Refiriéndose a los posibles casos de arcaísmos vivos en las hablas americanas, advertia Rufino José Cuervo: “¿Quiere decir esto que el castellano (o digámoslo mejor, el español) no ha tenido evolución alguna especial en América? Sostenerlo en absoluto sería desconocer la naturaleza misma del lenguaje" $^{18}$. Parece ser que hay, todavía hoy, quienes la desconocen. No, desde luego, Dámaso Alonso, quien supo evaluar debidamente la importancia de la modalidad americana de la lengua española frente a la castellana, hoy en día absolutamente minoritaria ${ }^{19}$.

1.3. En lo que respecta al vulgarismo $\longrightarrow$ al rusticismo- del español americano, cabe hacer dos consideraciones fundamentales: una, en relación con el concepto mismo de vulgarismo; otra, referente a las causas de ese supuesto vulgarismo. Atenderé a la primera de ellas más adelante, conjuntamente con la relativa al también supuesto arcaísmo del español americano, porque ambas calificaciones se deben a una misma actitud crítica que considero equivocada.

En lo que respecta a las causas históricas, sociales, del vulgarismo lingüístico de América, poco podria añadirse a lo dicho por Angel Rosenblat en $1964{ }^{20}$. Frente a la suposición $\multimap$ a la creencia - de que el español de América es una modalidad vulgar o rústica de la lengua espafiola a causa de que quienes la transplantaron al Nuevo Mundo eran personas muy incultas, de origen social bajo, demuestra Rosenblat que esa emigración española fue, al menos en su origen, de relativamente alto nivel cultural, superior en promedio al de las sociedades europeas de la época. A la América española, en efecto, no llegaron malhechores ni delincuentes. A partir de 1505 , las leyes de la Corona castellana lo prohibian muy explícitamente. Y antes de esa temprana fecha no debieron de ser muchos los delincuentes enviados a América. En la gran flota con que Nicolás de Ovando llegó al Nuevo Mundo - y en la cual

18 Cfr. El castellano en América, en el tomo II de sus Obras, Bogotá, Instituto Caro y Cuervo, 1954, pág. 541 .

${ }_{10}$ Antes de 1978, cuando se calculaba que el número de hispanohablantes superaba ya los 250 millones, habla escrito: $\alpha_{i}$ Qué pequeña parte de ese conjunto formamos los españoles! ... ¿Qué representa, frente a ese conjunto, el número de españoles? Casi, casi, sólo la séptima parte. Dicho de otro modo: por cada español vivo existen en el mundo otros seis hombres cuya lengua es la misma muestra.» (Cfr. «El español, lengua de centenares de millones de hablantes», en la Memoria del I Congreso Internacional de Lengua Española, ed. por Manuel Alvar, Las Palmas de Gran Canaria, 1981, pág. 421.)

${ }_{20}$ Cfr. «Bases del español en América. Nivel social y cultural de los conquistadores y pobladores del siglo xvis, en Actas de la Primera Reunion Latinoamericana de Lingüistica y Filologia (Viña del Mar, Chile, 1964), publicado por el Instituto Caro y Cuervo, Bogotá, 1973 (cfr. págs. 293-371). Trabajo rehecho y muy ampliado en el libro del propio A. Rosenblat, Los conquistadores y su lengua, Caracas, Universidad Central de Venezuela, 1977, págs. 7-89. 
viajaban más de 2.500 colonos, lo que hacia de ella la primera flota verdaderamente pobladora-, venía sólo un desterrado, que además no era ningún rufián analfabeto, sino un hidalgo gallego, criado de la reina Isabel la Católica, al que se castigaba alejándolo de la corte "por cierta cuestión" con un vecino de Jerez ${ }^{21}$.

Tampoco fueron campesinos, rústicos e ignorantes, la base de la población de Hispanoamérica. Algunos llegaron, sin duda, pero en cantidad muy pequeña, insuficiente para las necesidades de la nueva sociedad. Los campesinos suelen ser gente apegada a su propia tierra, como las plantas que cultivan, y su resistencia, además, a abandonar el terruño encontraría el respaldo de sus propios señores, reacios a perder tan necesaria mano de obra. Recuerda Rosenblat algunos testimonios fehacientes: en 1518, el padre Las Casas pidió autorización para llevar a América 3.000 labradores, "y no halló veinte" que quisieran pasar al Nuevo Mundo. En el Catálogo de pasajeros a Indias consta que, entre 1539 y 1559 (es decir, en época ya de paz, con la conquista de los territorios americanos en gran parte consumada, situación favorable para la emigración de campesinos, poco afectos a las armas), de un total de 4.540 asientos, sólo aparecen 25 labradores y un hortelano; en cambio, figuran 827 'hombres de letras' (clérigos, bachilleres, licenciados, etc.), lo cual —en relación con los 2.000 emigrantes cuya profesión consta- representa el $41 \%$, frente a sólo $1,3 \%$ de labriegos. Tan elevada llegó a ser la proporción de abogados residentes en el Nuevo Mundo, que ya en 1513 Núñez de Balboa pidió al Consejo de Indias que no se permitiera viajar a América a más licenciados, a causa de las complicaciones y problemas que originaban con sus pleitos y litigios, en tanto que rogaba que se remediase la falta de labradores y artesanos (carpinteros, sastres, herreros, etc.).

La excelencia social - y cultural - de la corriente migratoria hacia el Nuevo Mundo no fue hecho fortuito, sino propiciado conscientemente por la Corona, "porque — según explica Gonzalo Fernández de Oviedo- los Católicos Reyes, siempre desearon que estas tierras se poblaran de buenos, pues de todo lo que tiene buen principio se espera el fin de la misma manera" 22 .

La sociedad española de aquel entonces respondía favorablemente al propósito de los Reyes Católicos. En 1514, Pedrarias Dávila había reclutado ya un buen contingente de hidalgos cuando, al llegar a Sevilla, "halló dos mil mancebos nobles, lucidos y bien aderezados, y le pesó mucho de no poder

\footnotetext{
21 Rosenblat, pág. 13 del libro citado en la nota anterior.

22 Rosenblat, Los conquistadores, pág. 22.-Y así, wentre los propios criados de sus Casas Reales, de quien más conocimiento y experiencia tenlan, escogfan y los enviaban a esta isla [la Espafiola] con cargos e oficios, por que se ennobleciesen y hobiesen principio y mejor fundamento $\mathrm{y}$ origen las poblaciones della, y principalmente esta cibdad [Santo Domingo]: no de pastores ni salteadores de las sabinas mujeres, como los romanos ficie ron, sino de caballeros y de personas de mucha hidalguía e noble sangrew.
} 
llevar a todos". Pedro de Alvarado llegó al Perú con 500 hombres, "los más dellos, caballeros muy nobles, de la flor de España", en palabras de Francisco López de Gómara.

$\mathrm{Y}$ aun los emigrantes incultos participaban del deseo de "ennoblecer las Indias", tantas veces atestiguado en los documentos de la época. A los muchos que reúne y menciona Rosenblat cabría añadir el breve - pero preciso y sintomático - testimonio que proporciona Baltasar Dorantes de Carranza, refiriéndose ya a la Nueva España, cuando sostiene "Que los conquistadores son hidalgos ... Que la gente que después fue viniendo ennobleció el Reino y lo illustró" ${ }^{23}$. Gracias a ese afán ennoblecedor, de superación, Santo Domingo contó con universidad desde 1538, y Lima y México desde $1551{ }^{24}$; la imprenta funcionó en la Nueva España desde 1535 ; la ciudad de México tuvo catedral antes que Madrid, y en Santiago Tlatelolco, a mediados del siglo xVI, se enseñaba a los jóvenes indígenas griego y latín...

En las cortes virreinales de México y de Lima se alcanzaron niveles culturales muy altos. A este respecto, escribe Menéndez Pidal: "La ciudad de Méjico fue, naturalmente, guía soberana en la formación del lenguaje colonial más distinguido. Prodigio de asimilación cultural, único en la historia de las naciones colonizadas, ostentó muy pronto un nivel de vida espiritual y material comparable al de las mayores ciudades de la metrópoli" ${ }^{25}$. Ese afán de superación, de ennoblecimiento individual y colectivo, llamó la atención del Inca Garcilaso, quien lo atestigua —con justa admiración — en los Comentarios reales: "los que entran en aquella tierra, por humildes que sean, luego que se ven dentro sienten nueva generosidad y nuevas grandezas de ánimo ... lo cual no deja [de] ser bizarría y braveza española" ${ }^{26}$.

$\mathrm{Y}$ ese afán de superación, de hidalguización, se reflejaba, naturalmente -dentro del plano lingüístico-, en el empleo cuidadoso y aun refinado de

23 Afirmaciones que explica en la pág. 12 de su Sumaria relación de las cosas de la Nueva España, ed. de José M.* Agreda y Sánchez, México, 1902: «No tiene duda, y esto es verdad, Exmo. Príncipe, que aunque en los conquistadores hubo algunos hidalgos, ahora lo son por la presunción todos, porque toda hidalguía de su naturaleza y cosecha tuvo sus principios de los hechos y servicio del Rey; en conformidad de lo cual dize fray Gerónimo Roman en sus Repúblicas, a 115 foxas: que los Conquistadores de la Nueva Spaña y Pirú son hidalgos a la antigua de devengar quinientos sueldos. Mas la gente que despues fue viniendo y poblando el reino le ha luzido mucho, y entremetidose con los mesmos Conquistadores por casamientos y parentesco, con que ya son todos casi unos."

is Recuérdese que la Universidad de Harvard se fundó en 1636, un siglo despues que la dominicana.

2s Ramón Menéndez Pidal, «Sevilla frente a Madrid. Algunas precisiones sobre el espafiol de América», en Estructuralismo e bistoria: Miscelánea Homenaje a André Martinet, vol. III, Universidad de La Laguna, 1962, pág. 158.

${ }_{20}$ Segunda parte, Lib. II, cap. XVI.-Grandeza de ánimo que también quedó plasmads en las dimensiones - grandiosas - de lo que aquellos hombres hicieron en América, especialmente en arquitectura y urbanismo. 
la lengua. De los testimonios que de ellos conocemos, dos son ya famosos por precisos e inequívocos: el del doctor Juan de Cárdenas, inquieto médico andaluz, y el del también cachupín Bernardo de Balbuena. El primero de los cuales se admiraba, ya en 1591, del primor, de la delicadeza, del "estilo retórico, no enseñado ni artificial, sino natural" de que hacían gala los hablantes americanos, superando ampliamente en el uso de la lengua a los peninsulares ${ }^{27}$, en tanto que el segundo, más concisa - pero no menos explícitamente- caracterizaba a la ciudad de México, pocos años después (1604), diciendo que "es ciudad de notable policía / y donde se habla el español lenguaje / más puro y de mayor cortesania, / vestido de un bellísimo ropaje / que le da propiedad, gracia, agudeza / en casto, limpio, liso y grave traje" ${ }^{28}$.

Parecería, pues, prudente pensar que, de ser verdaderamente rústico o vulgar el español hablado en América, ello no sería consecuencia de la escasa o nula cultura de sus conquistadores y primeros colonizadores, no obstante que el panorama presentado por el profesor Rosenblat pudiera reflejar una visión algo parcial o un tanto unilateral de la realidad. Cabe imaginar, en efecto, que la calidad o nivel cultural de los emigrantes no hubiera sido la misma en todas partes ni en todas las épocas. No lo fue, evidentemente. Los emigrantes más cultivados tendrían acomodo en alguna de las "grandes y famosas ciudades de Indias", en tanto que los menos preparados intelectualmente habrian de buscar fortuna en territorios menos concurridos y disputados. $\mathrm{Y}$ en las centurias posteriores a la de la conquista no cabe duda de que a América irían llegando desheredados de la fortuna de escasa formación cultural. De todo ello hay abundantes testimonios, de que sólo recordaré aquí

27 Escribía: «Para dar muestra y testimonio cierto de que todos los nacidos en Indias sean a una mano de agudo, tracendido y delicado ingenio, quiero que comparemos a uno de los de acá con otro rezién venido de España, y sea ésta la manera: que el nacido en las Indias no sea criado en alguna destas grandes y famosas ciudades de las Indias, sino en una pobre y bárbara aldea de Indios, solo en compañfa de quatro labradores, y sea assi mesmo el cachupín o rezien venido de España criado en aldea, y júntense éstos que tengan plática y conversación el uno con el otro; oyremos al Español nacido en las Indias hablar tan pulido, cortesano y curioso, y con tantos preámbulos, delicadeza y estilo retórico, no enseñado ni artiticial, sino natural, que parece ha sido criado toda su vida en corte, y en compañía de gente muy hablada y discreta; al contrario verán al chapetón, como no se aya criado entre gente ciudadana, que no ay palo con corteza que más bronco y torpe sea... Pues venga agora una muger de España, y entre en conversación de mu. chas damas de las Indias, al momento se differencia y conoce ser de España, solo por la ventaja que en cuanto al tracender y hablar nos haze la Española gente nacida en Indias a los que de España venimos. Pues pónganse a dezir un primor, un offrecimiento o una razón bien limada y sacada de punto, mejor biva yo que aya cortesano criado dentro de Madrid o Toledo, que mejor la lime y componga (Problemas y secretos maravillosos de las Indias, México, Pedro Ocharte, 1591, fols. $176 v{ }^{\circ}-117 v 0^{\circ}$ Ed. facsimilar, Madrid, Cultura Hispánica, 1945).

${ }^{28}$ Cfr. Grandeza mexicana, ed, de Francisco Monterde, México, UNAM, 2." ed., 1954, pág. 129. 
un par de muestras. Ya Hernán Cortés escribía a Carlos V: "es notorio que la más de la gente española que acá pasa son de baja manera, fuerte y viciosos de diversos vicios y pecados"; y el bachiller Luis Sánchez afirmaba que "todos cuantos pasamos a Indias vamos con intención de volver a España muy ricos, lo cual es imposible, pues de acá, de nuestra tierra, no llevamos nada y allá holgamos, sino a costa del sudor y sangre de los indios". Fernández de Oviedo sostiene, en su Historia general y natural, que los españoles venidos a las Indias son "por la mayor parte más cobdiciosos que continentes, e más idiotas que sabios, e más envidiosos que comedidos, e más personas de baxa sangre que hidalgos e ilustres". Por su parte, Juan López de Velasco consigna en su Geografía y descripción universal de las Indias que comúnmente "se han inclinado pasar destos reinos a aquéllos los hombres enemigos del trabajo, $\mathrm{y}$ de ánimos y espíritus levantados. y con codicia más de enriquecerse brevemente que de perpetuarse en la tierra, no contentos con tener en ella segura la comida y el vestido" 29 .

De todo habria, indudablemente ${ }^{30}$. Como en todas partes y como en la misma España. Pero lo que no debe olvidarse es la elevada proporción de hombres letrados y aun verdaderamente cultos entre los que hicieron la conquista y primera colonización de América, lo cual determinó que las colonias españolas del Nuevo Mundo no fueran notoriamente refugio de delincuentes, ni destierro de criminales, ni asilo de muchedumbres analfabetas, sino virreinatos que llegaron a alcanzar sorprendente nivel cultural. Tildar de vulgar o de rústico a todo el español de América es incurrir en generalización y simplificación caprichosa y falsa.

1.4. En la intensa influencia de las lenguas indígenas del Nuevo Mundo se suele ver otra de las características definitorias del español americano. Esta enorme modalidad de nuestra lengua estaría fuertemente coloreada de amerindismo.

Incuestionable parece ser tal influencia; lo que se debe analizar y precisar es su grado o intensidad. A lo largo de muchos años he atendido a esta

29 Comida y vestido *que a ninguno - continúa diciendo- en aquellas partes le puede faltar con una mediana diligencia que ponga en llegando a ellas, siquiera sean oficiales o labradores, o siquiera no lo sean, olvidados de sí se alzan a mayores y se andan ociosos y vagamundos por la tierra, hechos pretensores de oficios y repartimientos». (Cfr. Artemio del Valle-Arizpe, «Andonza mía [México en el Siglo xvi]», en Los cimientos del cielo. Antología del cuento de la ciudad de México, Paulo G. Cruz [ed.], México, Plaza y Valdés Editores, 1988, pág. 133.)

so Cosa que, por supuesto, advertía el propio Rosenblat: «Claro que después del siglo XVI acudieron, a un continente ya casi domesticado, sectores más bajos de la población, sobre todo con el movimiento inmigratorio de los siglos XIX y Xx. Pero se incorporaron - siempre con algunas aportaciones - a una sociedad hispanoamericana ya constituida en su base lingǘrstica, desde el siglo Xvi» (Los conquistadores, pág. 89). 
cuestión, y he podido advertir cómo ha ido siendo ella matizada y sopesada más objetivamente. Hace bastante tiempo que se superaron los entusiasmos indigenistas de los primeros estudiosos del español hablado en América, para quienes todo fenómeno lingüístico americano que no fuese propio del español europeo normal corría el peligro de ser atribuido a la influencia de los sustratos indoamericanos ${ }^{31}$. No obstante ello, hay todavía no pocas personas que piensan que, de cualquier modo, la influencia de los sustratos amerindios es muy importante y profunda, al grado de resultar ellos básicos en cuanto determinantes de las diferencias regionales existentes entre los diversos dialectos hispanoamericanos ${ }^{32}$. No falta tampoco quien se incline a restar toda importancia a esa interferencia lingüística.

Dada la amplitud y la complejidad del asunto, trataré aquí de resumir muy sucintamente mi punto de vista sobre él, atendiendo de manera particular al caso concreto del español mexicano, por haber sido México territorio en que la lengua castellana se encontró con diversos idiomas amerindios de gran importancia, situación que puede ejemplificar lo sucedido en otras áreas de Hispanoamérica, acaso menos estudiadas todavía.

Ante todo, creo que es necesario distinguir entre las situaciones y los efectos del sustrato lingüístico en sentido estricto, y las situaciones y consecuencias del adstrato o de casos de bilingüismo. En la primera situación se encuentran todavía hoy países como el Paraguay ${ }^{33}$ o regiones particulares como la Península de Yucatán; en el segundo, la mayor parte de las grandes urbes americanas y de los territorios en que las lenguas indígenas han desaparecido total o casi totalmente. Este español usado por los hispanoamericanos monolingües es el que marca la pauta de la vida y de la marcha de nuestra lengua en América; en él la interferencia de los sustratos amerindios es, lógicamente, mucho menor que la que puede descubrirse en el habla

s1 Cfr. R. Lenz, «Beiträge zur Kenntnis des Amerikanospanischen», en $Z R P b, \mathrm{XVII}$, 1893, págs. 188-214, traducido al español por A. Alonso y A. Lida en la BDH, VI, 1940, págs. 209-258.-El propio Alonso hizo ver cuán equivocado estaba Lenz, demostrando que todos los fenómenos que éste había atribuido a la influencia araucana eran de origen hispánico y se usaban en el español general o, al menos, en el dialectal, tanto en España como en América. (Cfr. «Examen de la teoría indigenista de Rodolfo Lenz», RFH, I, 1939, págs. 313-350.)

s2 Como había dicho Pedro Henríquez Ureña al relacionar las cinco grandes zonas lingüísticas de Hispanoamérica con las cinco lenguas indoamericanas en ellas predominantes: náhuatl, lucayo, quechua, araucano y guaraní. (Cfr. su «Observaciones sobre el español de América», RFE, VIII, 1921, pág. 360.) Relación que ya pusieron en entredicho algunos de sus contemporáneos, según he tratado de mostrar en mi ponencia sobre $\star$ Henríquez Ureña y la delimitación de las zonas dialectales de Hispanoamérica», Cuadernos de la Facultad de Humanidades, Río Piedras, Universidad de Puerto Rico, 13, 1985, págs. 31-48.

ss Cfr. Germán de Granda, Sociedad, bistoria y lengua en el Paraguay, Bogotá, Instituto Caro y Cuervo, 1988 (con abundante bibliografía sobre el español paraguayo). 
de indígenas bilingües, cuya lengua materna sigue siendo la aborigen. El problema del bilingüismo no es, propiamente, el que se debate al tratar de caracterizar al español de América, sino el problema la influencia de los sustratos amerindios en el español general del Nuevo Mundo (si es que tal cosa existiera en la realidad).

Pues bien, en mi opinión, tal influencia es pequeña o superficial por cuanto que no ha alterado prácticamente en nada el sistema gramatical - la estructura fonomorfosintáctica- de la lengua española.

1.4.1. Ninguno de los fenómenos fonéticos del español mexicano que se han atribuido a la influencia del sustrato indígena - por lo común, del náhuatl- tiene en realidad tal origen ${ }^{34}$. $\mathrm{Ni}$ la "peculiar" /s/ mexicana - de tensa articulación, timbre agudo y larga duración - está influida por la africada nahua $/ \hat{\mathrm{s}} /$, como creyeron Amado Alonso y Pedro Henríquez Ureña; ni la debilitación extrema que llega inclusive a la pérdida de vocales átonas, en casos como $a n t^{\circ} s$, pes's, ch'star, que Angel Rosenblat, entre otros, atribuyó a interferencia del sistema fonológico nahua; ni la asibilación de la vibrante simple $/ \mathrm{r} /$ en final de palabra, especialmente ante pausa - salir, comer-, que Bertil Malmberg suponía estar condicionada por la lengua de los aztecas; ni mucho menos la peculiar entonación que caracteriza a los diversos dialectos hispanomexicanos, dependen de las lenguas aborígenes de México, según he tratado de mostrar en varios estudios ${ }^{35}$. Y cuando se alude a la neutralización -o confusión- de $i / e$ y de $u / o$ en el habla de los indígenas de los Andes del Perú, Bolivia y el Ecuador —en casos como pichu 'pecho', tribul 'trébol', etc.-, no hay que olvidar que tales confusiones son propias del español de hablantes bilingües que tienen al quechua como lengua materna, pero que tales neutralizaciones no se producen en la norma lingüística general —en el español común- de ninguno de esos tres países.

\footnotetext{
34 Excepción hecha del fonema palatal fricativo sordo /š/ que figura en un número muy limitado de voces mesoamericanas, como mixiote [mišjóte], ixtabentún, xixi, y alguna otra; o del sonido - no propiamente ya fonema- dentoalveolar africado sordo [ $\hat{\mathrm{s}}$ ] -escrito $t z$ - que aparece en la onomástica o la toponimia, en casos como Quetzalcb́atl - Janitzio, y en una sola voz común: quetzal; y, por último, la particular manera de articular la secuencia $« t+1$ e en el habla mexicana en una misma sflaba, con $l$ licuante de $t$ explosiva, en usos como a-tlas, ix-tle o tlaco.

3s Recogidos gran parte de ellos en el libro de Estudios sobre el español de México, México, UNAM, 2." ed., 1983, y en el de Estudios de lingüistica bispanoamericana, México, UNAM, 1989. Mis objeciones a la tesis general de Ángel Rosenblat en torno a la decisiva influencia del sistema fonológico nahua sobre el español mexicano (cfr. "Contactos interlingüísticos en el mundo hispánico: el español y las lenguas indígenas de América», en las Actas del II Congreso Internacional de Hispanistas, Nimega, Instituto Español de la Universidad, 1967, págs. 109-154) se publicarán, con el título de «La originalidad del español americano y las lenguas amerindias», en las Actas del II Congreso Internacional de Historia de la Lengua Española, celebrado en Sevilla del 5 al 10 de marzo de 1990.
} 
1.4.2. Si la interferencia del sustrato amerindio es reducidisima en el dominio de la fonética, menor aún es, quizá, en el de la morfosintaxis. El único morfema de indudable origen nahua usado en el español de México es el sufijo -eco formador de gentilicios: guatemalteco, yucateco, tlaxcalteca, etc. Pero no tiene tal origen el otro sufijo homófono de origen hispánico usado para designar defectos físicos o morales - patuleco, bireco, cacareco, temble$q u e$, etc. - , según habia imaginado erróneamente Max Leopold Wagner ${ }^{36}$, apropiándose de una suposición de Rufino José Cuervo. No sé a ciencia cierta si el sufijo o simple terminación $-i(n)$ che de mexicanismos como metiche 'entrometido', pedi $(n)$ che 'pedigüeño', caguiche 'cagón', etc., podría tener relación con el sufijo reverencial y afectivo nahua -tzin [ŝin] o si, al menos, pudo éste haber favorecido el empleo de una formación interna hispánica ${ }^{37}$. Por su parte, el empleo de los sufijos $-l a$, e $-y$, de origen quechua, está limitado a hablas locales, y no forman ellos parte, en realidad, del sistema morfológico normal del español peruano o argentino. Mayor arraigo parece tener, en el español ecuatoriano, la perífrasis "dar + gerundio" de diversos significados -especialmente exhortativo-, que traduce una construcción quechua similar ${ }^{38}$. No sería mucho más lo que pudiera añadirse a esta exigua enumeración.

1.4.3. Pero las cosas cambian cuando se pasa al dominio lexicográfico. Es en él donde la influencia de las lenguas indoamericanas - se trate o no de verdadero fenómeno de interferencia o sea simplemente trasiego de préstamos léxicos- se hace más patente e incuestionable. Pero ello no permite incurrir en exageraciones apasionadas, como las de algunos indigenistas para quienes una milagrosa desaparición de los nahuatlismos usuales hoy en el español de México sumiría a los hablantes de este país en un "caos horrible" ${ }^{39}$. Creo sinceramente que no se produciría tal caos, sino sólo algunos ligeros inconvenientes. En efecto, en el habla total de la ciudad de México, con sus casi 18 millones de habitantes de todas clases y condiciones, sólo

36 Cfr. «El sufijo hispanoamericano eco para denotar defectos físicos y morales», NRFH, IV, 1950, págs. 105-114.-Creo haber refutado la tesis de Wagner en el artículo «Sobre el origen del sufijo -eco como designador de defectos», en Sprache und Geschichte: Festschrift für Harri Meier, München, Wilhelm Fink Verlag, 1971, págs. 305-312.

37 Me he ocupado de ello en un artículo sobre «Mex. -che, $-i(n)$ che ¿nahuatlismo? que se publicará en la NRFH, en el vol. de Homenaje a Antonio Alatorre.

${ }_{38}$ Cfr. Humberto Toscano Mateus, El español en el Ecuador, Madrid, CSIC, 1953, págs. 284285.

39 $4 \mathrm{Si}$ desaparecieran del lenguaje español que hablamos los mexicanos, todas las voces en dicho lenguaje incluidas y que tienen su origen en el idioma náhuatl [o en otras lenguas indígenas mexicanas], se produciría un caos verdaderamente horrible por la situación en que tal desaparición hubiera de colocarnos» (Darío Rubio, Refranes, proverbios $y$ dichos y dicharachos mexicanos, México, 2." ed., 1940, vol. I, págs. xxii-xxiii). 
tienen cabida poco más de 300 vocablos - correspondientes a 237 lexemas-, algunos de ellos de uso muy restringido, de manera que no llegan siquiera a 200 voces - procedentes de sólo 166 lexemas amerindios- las que se conocen y usan en el habla urbana de México. Y, lo que es aún más revelador, la vitalidad de esos 300 vocablos, su índice de aparición en la cadena hablada o escrita ${ }^{40}$, apenas alcanza el $0,09 \%$ de la muestra total ${ }^{41}$. La mayor y más importante -en cuanto generalizada dentro de la lengua española generalcontribución léxica de las lenguas indoamericanas al enriquecimiento de la española la proporcionaron las lenguas de las Antillas, tahíno, arahuaco y caribe, por haber sido las primeras que entraron en contacto con la lengua castellana ${ }^{42}$. Esos antillanismos quedaron integrados, desde antiguo, al vocabulario hispánico general, de manera que no contribuyen a caracterizar al español americano frente al europeo.

No cabe, sin embargo, duda de que donde más se ha dejado sentir la huella de las lenguas amerindias, ha sido en el dominio del léxico, especialmente en el caso de hablas regionales o locales, en las cuales el número de voces indoamericanas particulares se eleva un tanto. Es el sector léxico el más superficial dentro de la estructura lingüística de todo idioma, y su variedad no representa peligro grave para la homogeneidad y estabilidad del sistema. El edificio gramatical de la lengua española - su estructura morfosintáctica y aun la fonológica- se mantiene firme y compacto, sin que la influencia de los idiomas amerindios haya penetrado apenas en él.

1.5. Consideremos, por último - aunque también haya de ser rápida y sucintamente- la quinta característica del español americano: su arcaísmo. De nuevo convendrá establecer una bipartición en el tratamiento del tema: de un lado, el origen o la causa de ese supuesto arcaísmo; de otro, el concepto mismo de arcaismo, al que sumaremos — como en páginas anteriores anunciaba- el de vulgarismo.

1.5.1. No es ya necesario detenerse a considerar y a mostrar con nuevos y amplios razonamientos cuán injustificado resulta atribuir ese arcaísmo al "medievalismo" del castellano transplantado al Nuevo Mundo por los des-

$40 \mathrm{La}$ investigación de que proceden estos datos abarcó tanto la lengua hablada en todas sus manifestaciones - culta e inculta, formal, informal, familiar, de todas las generaciones sucesivas de hablantes, etc.-, cuanto la lengua escrita, en sus diversas modalidades - familiar, periodística, literaria en todos sus géneros.

${ }_{41}$ Proporción que ascendía al $0,4 \%$ al incluir en el recuento todos los topónimos, patronímicos y gentilicios, México y mexicano entre ellos.-Cfr. Juan M. Lope Blanch, Léxico indigena en el español de México, El Colegio de México, 2." ed. aumentada, 1979.

4 Cfr., a este respecto, Paciencia Ontañón, «Observaciones sobre la génesis de algunos indigenismos americanos», $A L$, XVII, 1979, págs. 273-284; y Juan M. Lope Blanch, «Antillanismos en la Nueva España», $A L, \mathrm{XIX}, 1981$, págs. 75-88. 
cubridores y conquistadores. Ya lo hizo Amado Alonso, en lineas de corrosiva ironía, que no me resisto a transcribir aquí en beneficio de desmemoriados: "Lo he leído en varios de los filólogos que se han ocupado del tema: que el español de América tiene por base el español anteclásico. Dos errores o confusiones son los responsables: el primero es de orden teórico-lingüístico, la confusión tan general entre «lengua» y «lengua literaria», confusión combatida y acometida con todas armas desde hace medio siglo, pero que, al parecer, es inmortal... El segundo error es de orden histórico-lingüístico, y es el pensar (iqué maravillosa precisión!) que el español que hoy se habla en la extensa América es un derivado concretamente del idioma que en 1492 trajeron los compañeros de Cristóbal Colón en la Pinta, la Niña y la Santa María. No hacemos caricatura; son esos mismos filólogos los que despejan la duda aclarando que el idioma base es el anteclásico «del siglo xv». Como si la tripulación descubridora hubiera puesto en la Isabela o en la Española un huevo lingüístico, hubiera escondido un día en la tierra una invasora semilla lingüística que desde alli se hubiera ido extendiendo y multiplicando hasta cubrir las islas y los dos continentes" ${ }^{43}$.

Tenia toda la razón Amado Alonso - ya lo he dicho anteriormente ${ }^{4}$ al hacer esta festiva réplica. Decir que la base del español americano fue el castellano usado por los soldados durante la época de la conquista es absolutamente cierto. Pero no me parece acertado reducir tamaña empresa a su momento inicial, ni mucho menos identificar conquista con descubrimiento. La conquista - y la colonización - del Nuevo Mundo se realiza a lo largo de una centuria bien cumplida, y no en 1492, "a fines del siglo xv", como asienta Zamora Vicente. Baste recordar que la lengua española - todavía sólo castellana - no llegó a las costas de México sino hasta 1519. Y recordemos, además, algunas otras fechas que apuntalan el razonamiento histórico de Amado Alonso: La conquista del Perú se inicia realmente en 1532 ; la fundación de Bogotá data de 1538, y la de Santiago de Chile se produce en 1541. $\mathrm{La}$ ciudad de $\mathrm{La} \mathrm{Paz}$ se funda en 1549, tres años después que la de Cuenca, en el Ecuador, y algo más tarde la de Caracas (1562). Y si bien la villa de la Asunción data de 1536, la colonización del Paraguay no la inician verdaderamente los jesuitas sino hasta 1608. Inclusive la colonización de las An-

43 Y añade: «Esa tan extraña como auténtica concepción implica que Bernal Díaz y sus 450 compañeros de la campaña mejicana (1519-1522), Francisco Pizarro y sus 160 soldados conquistadores del Perú, Pedro de Mendoza y sus 1.200 fundadores del primer Buenos Aires (1536), etc., tuvieron que abandonar su idioma del siglo xvI y volverse al del siglo xv que los Pinzones habían depositado en la Española» (cfr. «La base lingǘstica del español americano», en su libro Estudios lingǘisticos. Temas bispanoamericanos, Madrid, 1953, págs. 10-11).

4 Cfr. «El supuesto arcaísmo del español americano», en el Homenaje a Menéndez Pidal, $A L$, VII, 1968-1969, págs. 85-110.-También incluido en mi libro de Estudios sobre el español de México, México, UNAM, 2:* ed., 1983, págs. 33-53. 
tillas es empresa que corresponde plenamente al siglo $\mathrm{xVI}, \mathrm{y}$ no al $\mathrm{xV}$, por cuanto que la población de la Española - de donde habrian de partir posteriormente las expediciones conquistadoras de las demás islas- se inicia, en realidad, en 1502, con la llegada de la gran flota de Nicolás de Ovando.

$\mathrm{Me}$ parece, pues, incuestionable que esa primera etapa histórica de la América española - la de las conquistas - coincide plenamente con la primera mitad del siglo xvi, no con los últimos años del xv. Sigue a ella la etapa, no mucho menos importante, de población y colonización de los territorios sometidos, la cual rebasa los limites finales del siglo xvi. Pero aun circunscribiéndonos a la época inicial de conquistas, habremos de convenir en que el español de los soldados y navegantes no correspondía ya, en el terreno del habla, al idioma literario de Juan de Mena ni al codificado por Nebrija en su Gramática de 1492, sino al plenamente renacentista de Garcilaso y Boscán, al de Carlos V y Juan de Valdés, o - si siguiéramos la costumbre de relacionarlo con la lengua literaria- al del Lazarillo de Tormes y de La Araucana de Ercilla, poema escrito, precisamente, al mismo tiempo que se desarrollaba la conquista de Chile.

Y claro está que sobre ese español de la conquista fueron cayendo después durante la etapa de población y colonización, sucesivas oleadas peninsulares, que traían al Nuevo Mundo las innovaciones lingüísticas que habían triunfado o que estaban gestándose en la metrópoli ${ }^{45}$. Nítidamente se diferencia el español americano del que los judíos expulsados de la Península Ibérica en 1492 llevaron a tantos rincones del Mediterráneo. Del judeoespañol sí puede decirse que tiene como base el sistema castellano del siglo xv, ya que la lengua de los sefardíes quedó desconectada de la peninsular, rotos sus lazos de comunicación, y abandonada a su propia suerte. Por ello, el judeoespañol no participó de las innovaciones peninsulares ni siguió la ruta

45 «Las colonias de América eran durante todo el siglo Xvi una real prolongación de la España peninsular. Olas y olas de españoles iban a las colonias y renovaban cada año la sangre idiomática. Muchas iban y venían. Lo que era nuevo en la Península saltaba el océano y en las colonias prendía como en su propio suelo: todos los barcos llevaban re mesas de libros españoles; comedias de Lope se representaban en los teatros coloniales casi en seguida de su estreno madrileño; las modas de vestir cambiaban en América conforme cambiaban en España. El idioma también: no como una servil reproducción, sino con la forma americana del cambio español. La base del español americano es la forma americana que fue adquiriendo en su marcha natural el idioma que hablaban los españoles del siglo xvi, los de 1500 y los de 1600, y unos decenios del xvir ... En la época de la conquista y de la colonización, el lenguaje español del siglo xv, en lo que tenía del siglo xv y no del siglo xvi (en lo que ya había salido del uso), estaba tan pesado y muerto e inoperante como el lenguaje del siglo x. Lo pasado y caducado no se cuenta por la distancia temporal, sino por su condición de no pertenecer al sistema lingülístico vivo. No perduran en América, ni menos son su base, ni la pronunciación del siglo xv (cambiada en el XVI), ni las formas verbales, ni las palabras ni las formas sintácticas que en España quedaron obsoletas en el siglo xvi» (A. Alonso, La base, págs. 12-13). 
recorrida por el castellano general. Pero no fue ése, ni mucho menos, el destino del español americano, según reconocen los más autorizados historiadores de nuestra lengua, como Rafael Lapesa. La colonización de América se inició "cuando el idioma había consolidado sus caracteres esenciales y se hallaba próximo a la madurez" 46. Y Ángel Rosenblat: "El español de América se ha constituido plenamente, en sus líneas fundamentales - sistema fonémico, morfológico-sintáctico y léxico- en el curso del siglo xvi" ${ }^{47}$. No puede, pues, seguirse atribuyendo el supuesto arcaísmo del español americano a un falso preclasicismo o medievalismo de origen.

1.5.2. A pesar de lo cual no sería imposible que el español de América hubiera terminado por resultar arcaizante, de acuerdo con la tesis de su fuerte conservadurismo. Pero ¿lo es en realidad? Quienes así lo piensan incurren en un grave error de método, que consiste en considerar "arcaica" o "vulgar" toda forma lingüística que haya caído en desuso en la norma actual castellana o que en ella haya descendido a la categoría de vulgar, identificando así, muy impropiamente, el dialecto castellano de nuestro tiempo con la lengua española. Hoy no es ya posible identificar la lengua española con alguna de las modalidades particulares que la integran ${ }^{48}$. Arcaica o vulgar será, solamente, una forma lingüística que haya caído en desuso en todas o en la gran mayoría de las normas regionales de alto prestigio o que haya sido arrinconada en ellas por su rusticismo o por su vulgarismo, pero no las formas que, habiéndose perdido o degradado en la norma castellana, subsistan con vigor y prestigio de las normas americanas. Así, por ejemplo, el adjetivo liviano no puede considerarse, de ninguna manera, un arcaísmo mexicano - y de otras muchas hablas americanas- por más que en el habla de Madrid haya sido arrinconado por ligero; en realidad, lo que sucede en este caso es que la norma madrileña ha reducido el sistema al perder una distinción válida y útil de la lengua: liviano hace referencia al peso y ligero a la velocidad.

Es imprescindible superar toda actitud provinciana o localista, "de cam-

46 Cfr. su Historia, 8." ed., pág. 534.

47 Cfr. Los conquistadores, pág. 9.

48 De ello me ocupé hace ya muchos años. «La lengua española -el sistema lingüfstico general- está hoy constituida por las diversas hablas que la realizan cotidianamente en cada una de las regiones de Europa o de América donde se usa. Ella abarca tanto el habla de Castilla la Nueva (con sus diversas realizaciones -0 hablas - locales), cuanto el habla de Castilla la Vieja, de Andalucía, de las Islas Canarias, de México, de la Argentina, del Perú, de Costa Rica, etc. Identificar el habla castellana -el dialecto castellano [o, más concretamente, madrileño] - con la lengua española - no sólo general, pero ni siquie ra peninsular- no puede aceptarse, hoy en dfa, sino como excesiva presunción [localista]. Lo cual es independiente del diverso prestigio de que pueda gozar cada una de esas modalidades dialectales. (Cfr. el artículo citado en la nota 44, pág. 97.) 
panario", cuando de juzgar las realidades o fenómenos de la lengua española se trata. Si admitiésemos que liviano, o recibirse ${ }^{49}$ o el vuelto son arcaísmos por el simple hecho de que ya no los usa la norma castellana, adoptando una justificable actitud americanista podríamos decir que serían arcaísmos las formas castellanas estafeta de correos (i en la era de los jets!), o afeitarse (como si los hombres de hoy usaran afeites a la manera de sus antepasados de hace dos siglos) o estanco y otras cosas semejantes, por cuanto que han caído en desuso en las normas americanas o en algunas de ellas de alto prestigio.

Lo mismo cabe decir de los vulgarismos: si la diptongación de los hiatos aceptable en varias normas cultas de América (en casos como lión, pior, cuete, etc.) resulta vulgar para la norma española, no es menos cierto que la eliminación del fonema - $d$ - en la terminación -ado (en casos como cansao, asustao, soldao, etc.), común en castellano, resulta vulgar para la mayor parte de las normas cultas americanas. Como resultan vulgares las castellanas neutralizaciones de $\mathrm{k} / \theta$ (atto), d/ $\theta$ (carida $\theta), \mathrm{k} / \mathrm{b}$ (aksoluto), o la confusión de fallo ('sentencia') con falla ('defecto o falta') tan generalizada en el español europeo.

Los conceptos de arcaísmo y de vulgarismo son conceptos relativos, no absolutos ni objetivos. Cualquier hecho lingüístico no es ni vulgar ni exquisito en sí mismo; ello depende del prestigio que posea dentro de la norma correspondiente. $\mathrm{Y}$ por supuesto que el concepto de norma es también un concepto básicamente relativo. En la norma hispánica (del sistema lingüístico que es la lengua española) tan vulgares como las formas pior o cuete serán las formas cansao, atto o aksoluto, por la sencilla razón de que esa norma hispánica exige escribir peor o cohete y cansado, acto o absoluto ${ }^{50}$. Y $\tan$ válidas o actuales serán en ellas formas como recibirse, liviano, o el vuelto. cuanto estafeta, afeitarse o estanco, puesto que todas ellas están vivas en normas lingüísticas actuales de alto prestigio. Sólo formas como mur, fiuzia, ayuso, matarlo has, desque, endenantes, etc., son verdaderos arcaísmos o vulgarismos, dado que han sido olvidados o rechazados por todas las normas lingüísticas actuales de prestigio.

1.6. No atiendo aquí al problema del andalucismo de base, en ciertas regiones, como último rasgo caracterizador del español americano, por cuanto que ha sido tratado — analizado y discutido- mucho más abundante, por-

40 En el sentido de 'tomar un grado universitario', que se usaba *en España todavfa a fines del siglo pasadow (Zamora, Dialectología, pág. 427).

so Sobre la importancia - como norma rectora- de la lengua escrita, véanse los juicios que reúno en mi ponencia sobre $\alpha E$ l ideal de lengua y los países hispanohablantes», que aparecerá en las Actas del Primer Congreso Anglo Hispano: V Centenario, Huelva, 24-31 de marzo de 1992. 
menorizada y rigurosamente que los rasgos anteriores, por los más autorizados hispanistas de las últimas décadas ${ }^{51}$.

1.7. Como, ya en 1921, con sabia prudencia aconsejaba Henriquez Ureña ${ }^{52}$, al hablar del español de América conviene huir de toda generalización simplificadora, porque, de lo contrario, se corre grande riesgo de incurrir en graves imprecisiones o aun en lamentables errores.

51 A partir de Cuervo y de Henríquez Ureña, han intervenido en la discusión filólogos tan insignes como Menéndez Pidal, Amado Alonso, Tomás Navarro, Boyd-Bowman, Wagner, Lapesa, Rosenblat, Guitarte, Catalán, Alvar, Galmés, Canfield y algunos otros. Una sistemática historia del tema hizo Ángel Rosenblat en su ponencia sobre «El debatido andalucismo del español de América», en El Simposio de México (Actas, informes y comunicaciones) del Programa Interamericano de Lingǘstica, ed. por J. M. Lope Blanch, México, UNAM, 1969, págs. 149-190.

52 «En cualquier estudio sobre el castellano de América debe comenzarse por abandonar, siquiera temporalmente, las afirmaciones muy generales: toda generalización corre peligro de ser falsa. Diferencias de clima, diferencias de población, contactos con diversas lenguas indigenas, diversos grados de cultura, mayor o menor aislamiento, han producido o fomentado diferenciaciones en la fonética y en la morfología, en el vocabulario y en la sintaxis» (Observaciones, cit. en la nota 32, págs. 357-358). 